\title{
Homo Oeconomicus Quo Vadis? An Anthropological Introduction to the New Management Paradigm: The So-Called New Alternative Forms of Organization
}

\author{
Stephanie A. Krawinkler ${ }^{1}$ \\ University of Applied Sciences BFI Vienna
}

There is a paradigm shift happening in management and organizing practices in the corporate world. This article aims at giving an overview of various approaches so that the technical language is easier and accessible to business anthropologists. Then it offers a brief case study of Premium Cola followed by anthropological concepts and reflections of key topics that are addressed with this paradigm shift.

When I did an ethnographic study on an organization, something interesting happened. One day after the rivalry between two department managers in charge of different aspects of the electrician project management escalated, the workers who were assigned to the two departments came up with an idea. They considered themselves as one community all belonging to the same company, all doing similar tasks; "we the workers of Wire Inc." Therefore, they asked for not being divided anymore into two different departments that were measured against each other in regards of financial key figures. They wanted to cooperate and change the current formal structure. Interestingly, they had organized themselves, discussed it and presented it to the CEO. In this case we were in a traditional medium-sized, family owned Austrian company in 2009. The CEO calmed the workers and explained to them that this is simply not manageable and that the hierarchy structure is there for a reason. However, in the following weeks the communication processes were altered and there was more information shared with all levels in the organization. Moreover, the competition between the two department managers was reduced by interventions from the top management. Soon the situation calmed and daily life business was looked after. This consolidation of the workers was a big surprise to the CEO and the proposal also surprised me - even though spending quite some time with the employees I was aware of that they had a high level of identity with the company but did care less about who was their manager. This uprising from the lower part of the hierarchy with a proposal of a new form of organization made an impression on me and hence I followed the rise on alternative forms of organizations in the recent years.

\section{INTRODUCTION}

This article is going to present various concepts of the so-called new form of organizations and highlight aspects of it through the anthropological lens. "Such a comparative approach may help to recover 
the sense that other alternatives for organizing economic activity have existed and currently exist - from large-scale worker owned cooperatives to small-scale instances of community supported agriculture" (Foster, 2017: 128). Agile teams, Scrum, Sociocracy, and Holacracy are some of the names of the concepts that are summarized under the term without precise definition (Hauser, 2017: 9). These new types as diverse as they are in their details are united by a basic humanistic premise that human beings are able and willing to collaborate and to look out for each other and that they are able to perform without being constantly controlled by a superior. Czarniawska (2008: 92) underlines the curiosity of human beings and stresses that they don't resist change if they induce it themselves, in contrast to a commanded change.

The data origins from a thorough literature review, from some informal talks with people working with this new paradigm and from insights gained in a workshop with Christiane Seuhs-Schoeller (13.04. 2018), co-founder of the company Encode that uses and trains others in Holacracy. The various terms used in the scope of the new form of organizations are briefly described so that the terminology used in companies and in the management studies are familiar to the anthropologists as well. A case study is also presented showing a company with a different approach of management before I used anthropological concepts to figure out whether all of these ideas were really new and how anthropologist could assist organizations in implementing this paradigm shift.

\section{A Brief Historical Outline}

The homo oeconomicus has been used as a role model since it was first named by Eduard Spanger in 1914 and was made popular by the management theories of Frederic Winslow Taylor. The scientific management studies have been following the axiom that the human beings always aim at maximizing their individual benefit due to the scarcity of means. This logic of optimization is regarded as a unique and universal behavior. In case of a choice between two or more goods, the individual will make a rational choice. Even though empiric examples for the axiom are rare, they have been the base for the business and management education in the recent decades (Seiser, 2017: 27f.). Critiques of the concept of the homo oeconomicus have a long tradition in anthropology, i.e. from Malinowski (1961), Sahlins (1972) to Rogall/Gall (2015).

Considering the organizational theory, it is obvious that there has been some development since the bureaucracy of Max Weber and the Taylorism. The Human-Relation approach that originates from the famous Hawthorne Studies included the idea of informal organization structures in the general management theories. However, the Human-Relations-Theories have not replaced the Taylorism and Fordism, but they increased the range of methods and requested the managers to implement a different way of leadership. The next addition was the behavioral scientific decision theory which focuses, as the name already reveals, on decision processes building on the assumption that human beings are limited in regards to their capacity to process information and that they have a restricted readiness to engage in the organization. The situative approach focuses on the formal structure of organizations. The institutional economic approaches including the transactional cost theory broaden the organizational theories by an economic reason for existence of organizations, but, it implies that the actors are limited in their rationality, act opportunistically and are risk neutral (Schreyögg, 2016).

All these described forms of organization use a conception of humans that is comparable to Theory $\mathrm{X}$ by Douglas McGregor (1960). Workers are regarded as being lazy, reluctant to work and therefore need to be controlled and directed by the management. In addition, they avoid any responsibility and are only motivated by money.

As a contrast to the mentioned organizational theories, the widely cited system-theoretical approach that was influenced by Niklas Luhman in the 1980s (building on Ludwig von Bertalanffy, Norbert Wiener and Talcott Parson) also needs to be mentioned. This interdisciplinary approach is based on biology, cybernetics, anthropology, sociology and philosophy. In general terms, it regards organizations as social systems that are comprised of communication of decisions. This holistic approach is not easy in the economic implementation due to the suppression of the actors, their moral undifferentiated functioning, 
and the negotiation of targeted control. Nevertheless, there has been a strong interest in these principles and there are a number of process consulting companies offering help in implementing this approach. The system-theoretical approach has been popular in Europe in the recent years to bridge the gap between real life and the concept of the homo oeconomicus. Since 2000, worldwide decentralized management systems have emerged in organizations. The current new work movement covered with consultancies reinventing themselves with a new alternative organization structure (i.e. Neuwaldegg - Austrian consulting agency ${ }^{2}$, with a tradition in the system-theoretical approach) or being established using Holacracy (Dwarfs and Giants - another consulting agency; a spin-off from Neuwaldegg), shows that there is a demand for altered organizing practices.

\section{The New Paradigm of Management}

What drives this new paradigm of management ${ }^{3}$ ? From an organizational perspective, there are external and internal drivers of this change (Häusling, 2018). Externally, there are: technological change and digitalization (industrial revolution 4.0), increasing dynamics and complexity, the behavior of customers, and high level of competition. Internally, agility is driven by the bureaucracy and the low level of output, the need to attract new employees, the change of values and the increase of individualization.

The needs for adapting organization to the changed requirements of today's world are also covered by management literature: the most important one, leading the bestselling lists, is the book "Reinventing Organizations" by Frederic Laloux (2015). Pircher (2018) provides a timeline of the so-called new paradigm:

- Mid of $19^{\text {th }}$ century to mid of $20^{\text {th }}$ century: development of the term sociocracy and of the first sociocracy approach.

- 1970 Handelsbanken (Sweden): Jan Wallander decentralized the management of Handelsbanken and abandoned budget planning. Branches that consist of maximum 12 employees have budget authority and they have to follow two central goals: first, to have a higher return on equity than competitors in the region, and second, to maximize customer satisfaction. The bank belongs since many years to the most successful ones in the Europe and is highly ranked worldwide (Pircher 2018: pp. 31).

- Early 1970s Gerard Endeburg developed the concept of sociocracy and applied it in his own company, Endeburg Elektrotechniek (Netherlands).

- 1980: Semco (Brasilien).

- 1984: Frithjof Bergmann "New Work".

- 2000: worldwide a range of companies with decentralized organization emerge.

- 2001: Agile Manifest.

- 2006: Organizational operating system Holacracy.

- 2014: Laloux: "Reinventing Organizations" - Teal Organization.

- 2016 Wiki to "Reinventing Organizations". (Pircher, 2018: 28).

Even though the first documented implementation of alternative organization forms dated back to the early 1950s (Gore-Tex, Laloux, 2015: 129), they are currently talked about as the new alternatives. This might be because they have now reached a critical mass, being studied, and presented as role models with modular consulting support by various companies. Also following Czarniawska's concept of travelling ideas (2008: 92f), an idea has to be manifested (i.e. into a text, or a model) so that it can travel. Owing to the various drivers of change briefly described above, there is a demand for new ideas regarding organizing, which are then put into action. Repeated actions create an action pattern which might turn into an institution. This is precisely the trend that can be currently observed in management studies referring to the concept of new alternative form of organizations.

The next section will shortly explain the terms Sociocracy, Agile Manifesto, Holacracy, and Teal organizations that were used in the above timeline, as they form part of the lingo and concepts of new alternative organizations. 


\section{Sociocracy or Sociocratic Circle-Organization Method (SCM)}

The term goes back to Auguste Comte in 1851. It is also known as Dynamic Governance (in the United States) and was significantly further developed by Gerard Endeberg. He wanted a structure in his company Endeburg Elektrotechniek that was making decisions neither in a hierarchical nor a democratic manner. Influenced by Kees Boeke (a Dutch progressive educator and a Quaker, who applied sociocracy to his school) and the principle of the dynamic governance, he developed a new management and governance system based on a circle structure. There are four key principles (Sociocracy Group, w. Y.):

1. Consent is the rule for policy decisions. Consent is not to be confused with an agreement. It means there is no objection. This allows that one can consent, even though one is not $100 \%$ agreeing, as long as it is not affecting one's own work for the company's goals. Policy decisions include financial, physical, and human resources decisions. Arguments are a key and decisions due to power attempts or emotions can be avoided.

2. Circles are the arena for policy decisions. These circles are formed by all members of a decision-making entity (department, team, etc.) who are all equal. Day-to-day decisions are made by the operation leader, who is an equal member of the circle.

3. Double linking describes that the operation leader and a second appointed person from the circle are representing their circle in the next higher circle as full members. This interlinkage is particularly for Sociocracy and enables a communication flow including a vivid feedback loop across the whole organization making knowledge of the organization members throughout the hierarchy visible.

4. The open election process is used to assign roles and responsibilities with the consent method.

Sociocracy encourages decision making and it follows the two paradigms: 'Good enough for now' and 'Safe enough to try'. It is used in manifold organizations: production companies, software development companies, service industry, education sector, elder care homes and co-housing collaborations (Pircher, 2018: 29; Sociocracy, w.Y.).

\section{Agile Management}

The term agile has currently wide use in the management context. In 2001, seventeen software developers published the Agile Manifesto to establish a fundamental different work style. "Now, a bigger gathering of organizational anarchists would be hard to find, so what emerged from this meeting was symbolic - a Manifesto for Agile Software Development - signed by all participants" (Highsmith, 2001). The manifest originally addresses the IT sector but has since then found implementation in other fields as well.

"We are uncovering better ways of developing software by doing it and helping others to do it. Through this work we have come to value: Individuals and interactions over processes and tools; Working software over comprehensive documentation; Customer collaboration over contract negotiation; Responding to change over following a plan. That is, while there is value in the items on the right, we value the items on the left more" (Beck et. al. 2001, highlighted in the original).

The seventeen signatories also known as Agile Alliance ${ }^{4}$ are named personally on the website, which provides the twelve key principles of agile working: amongst them are putting the client into the focus, trusting the employees that they can deliver, a preference of face-to-face communication and simplicity (not doing things not needed) and regular team reflection (Beck et. al., 2001). The initiators are interested in spreading their work conception and providing their information in 68 languages. Their manifesto summarizes how they perceived their own work environment and their values: "we all felt privileged to work with a group of people who held a set of compatible values, a set of values based on trust and respect for each other and promoting organizational models based on people, collaboration, and building the types of organizational communities in which we would want to work" (Highsmith, 2001).

Even though the challenges that require agility are increasing, surveys reveal that only few organizations have yet fully implemented agility. It is more likely that only certain areas of the business 
are transformed into agile teams. In management literature, it is reported that the companies which have done so, report financial and non-financial improvements resulting from the agile workflow (Pircher, 2018: 34f).

\section{Holacracy}

Holacracy is a new paradigm of organization that was established in 2007 by two Americans, Brian Robertson, a software developer, and Tom Thomison. They found the company Holacracy one that owns the rights for the legally protected term "Holacracy" and offers training and consultation. Brian Robertson took courses in Sociocracy and hence especially the circle structure and the governance process, which shows the influence. There were also inspirations from the agile management, particularly the iterative governance, the adaptive processes and the self-regulation and also the influence of David Allen's concept of how to get things done (2001). In their own words: "Holacracy ${ }^{\circledR}$ is a self-management practice for running purpose-driven, responsive companies" (HolacracyOne, 2018). The core of it is the so-called constitution ${ }^{5}$ that entails the rules, structures and processes according to which a holacratic organization functions. This way it provides a framework for the whole organization, providing clarity and security. Central to the whole concept is the distinction between role and person.

A person can hold several roles and/or a role can be distributed among a number of people. Each role has a clear purpose, domain and accountabilities. Other essential elements are the circle structure, the governance process and the operational process. It aims at clarity, i.e., who should make which decisions, what expectations are on them, and how the members really do the work. This information is stored publicly, meaning all the members of the organization and in some cases even partners from outside the organization have access to this information and are therefore able to quickly gain the overview that is able to help them with a certain issue. The decision-making power is distributed throughout the organization assigned to the various roles. The operation system orientates on tensions, because any rigidity is a given room for improvement. This paradigm was developed for organizations and companies. Holacracy is not a non-hierarchical operating system. But, as it is organized in circles and roles, the hierarchy looks very different to classical corporate hierarchies in pyramid shape. As an example, the following graph displays the so-called Holarchy and organigram of HolacracyOne. 


\section{FIGURE 1 \\ THE ORGRANIGRAMM OF HOLACARACYONE. (HOLACRACYONE, WY.B)}

HolacracyOne

Purpose: Evolve humanity's relationship to power.

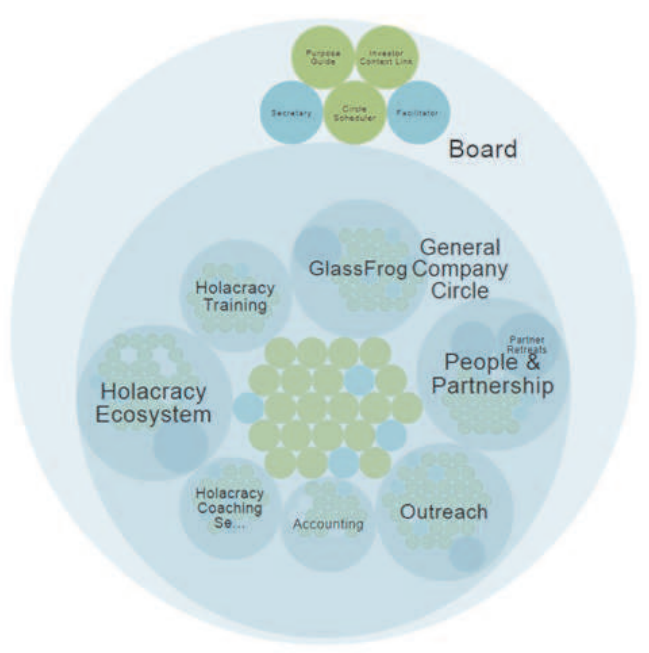

Filled role acore role Incomplete role

Glassfrog is the cloud-based platform provided by HolacracyOne to support the new organizing practice. It enables people for instance to gain insights of who is part of the organization and who performs which roles. Robertson indicates that Holacracy makes big reorganizations every few years obsolete because change happens constantly in small steps according to the needs. People in various companies using Holacracy have reported that it has changed their relationships with their co-workers. They experience each other's personality and value the clarity as well as the consequent safety. According to HolacracyOne, more than a thousand companies worldwide are using holacracy structures (Pircher, 2018: 36f, HolacracyOne, w.Y.). This model is sometimes criticized as inhumane. Robertson (2017) comments this on his company's blog with "the process is not designed to take care of everyone; it's designed to allow people to take care of themselves, through the processing of tensions", stating that Holacracy treats people as adults.

\section{Teal Organizations}

This is a term introduced by Frederic Laloux (2015) in his book "Reinventing organizations". He describes an evolutionary organizational development and the last step is the so-called Teal-Organization. It is characterized by self-organization and self-management. The organization's purpose is a key. Fear is replaced by trust. Inner rightness is used for a compass in decision-making, and life is regarded as a journey of unfolding building on strengths. This allows dealing gracefully with adversity, and wisdom beyond rationality, including other domains of information and knowledge like intuition, emotions, and the art of reasoning a paradox, striving for wholeness. His book is based on twelve organizations that have been running for up to several decades. What unites them is that they all see their organizations as living systems or organisms (Laloux, 2015: 56): "Life, in all its evolutionary wisdom, manages ecosystems of unfathomable beauty, ever evolving toward more wholeness, complexity, and consciousness."

Teal organizations share these characteristics (Laloux, 2015):

- Self-organized teams, coaches without profit and loss responsibility and no management authority.

- No middle management. 
- Minimum of staff functions.

- Coordination and knowledge exchange across teams.

- Trust versus control.

- Radically simplified project management.

- No organization chart, no job description, no job titles.

- Decisions are made using an advice process.

- Explicit assumptions.

- Transparency and access for all rule internal communications.

- Conflict resolution.

- Role definition and allocation.

- Performance management is happening at the team level.

- Dismissal happens but is very rare and it is usually seen as the last step in the meditated conflict resolution mechanism.

- Compensation \& incentives: peer-based processes and self-set salaries, reduced compensation inequality, as well as no incentives, but company-wide bonuses.

- Humanity is invited to work.

- Working environment is safe and open.

- Reflective spaces \& Storytelling

- Recruitment is done by team members.

- The onboarding involves training for new members to understand the organizations.

- Training is chosen and organized by the members themselves, is open to all members and employees might become trainers due to their knowledge and experience.

- The division between white-collar employees and blue-collar workers is suspended.

- Working time is linked to sincere commitments.

- Absence of competition (in internal reports and documents) due to truly living a purpose.

- Profit happens as a side-effect to fulfilling the purpose, paradoxically this increases profits.

- Strategy papers are replaced by the lived purpose. Thereby strategy emerges organically.

- Planning, budgeting: Sensing and responding replace predicting and controlling, i.e. in many organizations there are no financial targets, budgets are simplified, and profits are earned when doing the right thing.

- Inside-out approach: the purpose creates the offers and the marketing and product development are guided by intuition.

- Change happens naturally, wherever it is needed, almost effortlessly.

- Boundaries of the organizations are being transcended including customers and suppliers in the information flow.

This means that there still are structures, processes and leadership, and not everybody is equal in power but everyone is powerful, and it's not in the stage of experimentation (anymore). Teal organizations are: AES, BSO/Origin, Buurtzorg, ESBZ, FAVI, Heilgenfeld, HolacarcyOne, Morning Star, Patagonia, RHD, Sounds True, Sun Hydraulics (Laloux, 2015: 57ff.). They range up to several thousand employees and hence, show that this new paradigm is not limited by the scale of the organization and they are successful in various kinds simultaneously: "They provide a space in which employees thrive; they pay salaries above market rate; they grow year in and year out, and achieve remarkable profit margins; in downturns, they prove resilient even though they choose not to fire workers; and, perhaps most importantly, they are vehicles that help a noble purpose manifest itself in the world" (Laloux, 2015: 289).

Laloux's concept is largely influenced by Ken Wilber and his integral theory ${ }^{6}$. This might explain the strong notion of spirituality, human and organizational consciousness that are quite exceptional for management literature. 


\section{Characteristics of the New Forms of Management}

In these new types of organization, human beings are considered in the same way as in the Y-Theory by McGregor (1960): people naturally want to work and take over responsibility, as well as to be involved. They enjoy independence, can think for themselves, and are motivated by self-fulfillment. Hence, trust plays a major role in the functioning of this new paradigm of organization. However, they are different in their level of strictness and level of documentation. In addition, these systems span the whole range from self-called anarchic to very structured approaches. Common key factors are: purpose-driven, self-management, clear decision-making procedure, explicit conflict solution models, circles, empowering of the colleagues/members. What unites these different approaches is that they aim at facilitating verstehen ${ }^{7}$. This clearly indicates the turn from positivistic management studies to a new paradigm. One should distinguish whether a company introduces new/agile methods or a new paradigm of organizations. The first describes a company that implements some of the methods (e.g. agile Teams in the IT department) in certain areas of the business. Whereas the later describes the thorough alteration of the business organization, i.e., change of structure, transformation of the organization's goal (new: purpose-orientated), new roles and identities, changed responsibilities, altered decision-making processes, etc. This change process from the old paradigm to the agile management can be described as a liminal phase. This term coined by Victor Turner is the step of transition often embedded in a ritual. In this state, the previous status is obsolete, and there is a form of communitas ${ }^{8}$ amongst the participants. This means a kind of egalitarianism where everybody involved enters a new form of behavior. Very often the group is secluded from the rest of society - also to practice the new types of behavior. This is a common approach in case the new form of organizing is only introduced as pilot in a part of the company (Turner, 1969: 359f). People who have shared a stage of liminality can develop very strong bonds beyond the liminal phase. There are different views on whether it is feasible to run organizations with multiple, and in certain aspects, conflicting paradigms. ${ }^{9}$ Especially in the transition phase, this seems to be a common approach. Others speak from experience and say it was highly recommendable to switch an organization all at once.

Even though the classified new forms of organization (Pircher, 2018; Hauser, 2017) are often referred to being first established in the IT sector, the documented examples in the books from Pircher (2018), Hauser (2017), and Laloux (2015) show that there have been alternative management styles implemented decades ago in other industries as well.

The various cases show that the structure is not a one-fits-all as it depends on the industry where a business operates in (whether there is a need for quick innovation and adjustments or the relatively stable quality-assurance in manufacturing companies). Nevertheless, there is the shared mindset of Theory Y people based on trust. The clear decision of the $\mathrm{CEO} /$ business owner is to aiming at a different style of organization and the commitment to alter their own role(s) as well. A purpose, clear set of rules (including a defined decision-making process, an explicit conflict solution process), space for the how to be answered adeptly to the situational needs, a safe space to make mistakes. This leads to less control, less time spent in meetings, in many cases an elimination of traditional middle management and departments like the Human Resource departments and an alteration to traditional idea of how businesses function (budgeting, project management, contractual agreements). In addition, there is a whole range of tools that are used: non-violent communication by Marshall Rosenberg, Circles with a size around 12-15 people (which is in line with the number group dynamic studies have determined to be idle for face-to-face communication and the complexity involved), the Art of Hosting, Dragon Dreaming, Design Thinking, Storytelling, Silence, Lego Serious Play, Theory U, Appreciative Inquiry, Presencing et al., to just name a few ${ }^{10}$.

In the next section there is a brief case study presented to give a deeper understanding of how this might look in practice. 


\section{Case Study: Premium Cola}

The case that will be elaborated is Premium Cola, a German beverage company that runs counter general management ideas. The chosen company is very transparent on company representation about its special forms of organization and has been researched on by several people. Moreover, it has been active since many years and hence the objection, whether new forms of organizations are just a fashion, can be minimized. The case is drawn from various publications.

Premium Cola was founded by Uwe Lübbermann sixteen years ago. This company is remarkable, as they have no office, no bottling plant, is governed by an internet collective, and its principles, i.e. anti-volume discount, no commercial promotion and willingness to cooperate with others, have led to an operating system that is openly shared on their webpage, in public talks and is well researched. As a measurement of success Lübbermann refers to 1700 commercial partners without a single contract and no legal dispute in 16 years. Premium Cola has opened its structure to its suppliers, customers and collaboration partners. They all have a veto-right in the processes. The core value of Premium Cola is that all human beings are of equal value. The guiding principle is "Premium will ein faires, ökologisches und sozial tragfähiges Wirtschaftsmodell in hoher Qualität vorleben und verbreiten " ${ }^{11}$ (Premium, w.Y.).

The decision-making process is based on democratic consensus, with the CEO having the right to make decisions when the consensus is not reached or in urgent cases. In 16 years, this was the case happened three times. Decisions are described as being more intelligent and more social and as everybody agreed the implementations are efficient. It is described as having no hierarchy. However as the last sentence revealed even though it is an egalitarian organization, there is a little bit of a hierarchy in place. There are 12 people in the organizational team, 50 speakers in the various towns, and about 1700 commercial customers. All of them can participate in the collective. The feedback from external project partners is that it is less stressful and more efficient. Hence Premium Cola helps other organizations to implement this radical different management paradigm. Lübbermann's central task is to organize the cooperation between human beings. The company has also been labelled as a post-growth organization. At Premium Cola, the growth rate is limited to $30 \%$ per quarter which is still able to finance the next production cycle without the need of a bank. Moreover, the owner believes that from a certain size onwards, organizations cannot be governed socially compatible anymore and so he is keen on not growing too fast. Incorporating new members also is a challenge on a cultural level, as they need to be trained on the communication and organizational processes of Premium Cola and again this limits the scope of growth. The distribution of its beverages is limited to $600 \mathrm{~km}$ from the production place, due to the ecological impact and limited to the German speaking countries in Europe. The governance model of Premium Cola is shared with other organizations and is also applied internationally, i.e., it was introduced in Saudi Arabia (Gebauer, 2016; Premium, w.Y.).

Lübbermann clearly states that taking care of people and collaboration are not a new thing but that they went out of fashion. He relates to the new work movement critically, and emphasizes these are not new qualities. According to him, the change is happening too slowly (Bessen, 2018: Min: 7). The interlinkage between Premium Cola, its suppliers and commercial customer, or, in other words, between system and environment, corresponds to anthropological theories on societies which state that societies are not self-contained.

\section{Characteristics of the New Forms of Organization through the Anthropological Lens}

This new paradigm of organization in businesses makes space to explore the internal parts of culture, which are usually unconscious as defined by Edward Hall in 1976. The often-unconscious beliefs, values and thought patterns that strongly influence behavior are being made conscious in the new paradigm of organization. The key of how to do this is getting to know individuals and interact.

This following section highlights selected ideas of the new paradigm of organizing and provides an anthropological perspective on them. Turning to the examples of foreign societies to provide solutions for current challenges of one's own society is a time-honored practice of anthropologists. 


\section{Roles of Identity}

What unites the new concepts is that they require the willingness of the management to take on a new role, and may be even discontinue the privileged position they were having before. Moreover, employees and workers are urged to shift their self-concept. This might produce issues of identity for the managers and the workers. Mintzberg image of the quiet manager can be applied to this new paradigm of organizing: "Quiet managers need not empower their co-workers, whom they recognize as responsible adults. Quiet bosses inspire their co-workers, creating conditions that allow them to exploit their talents to the fullest. They strengthen social links among people, instead of calling them human resources. (...).Quiet bosses care about their co-workers" (Carniawska, 2008: 72). What only is to be taken into account is that they might not be called bosses anymore in the new form of organization. The companies share responsibility with their employees, so there is high level of trust into the reliability and confidence into their abilities. For the employees to be able to participate in decision processes they need access to the information. Organizations increase their level of transparence. Hierarchies change, become sometimes flatter and in some cases people even talk about the non-hierarchical organization (Hauser, 2017).

\section{Egalitarianism and the Matter of Power Distribution}

The question of equality leads to looking at egalitarian societies. Anthropology seconds Lübbermann's opinion that egalitarian structuring is nothing new. Graeber recently pointed out that in Mesopotamia, the Indus Valley and the Basin of Mexico, cities were organized on egalitarian lines a long time ago. There is no scientific evidence that large groups request a top-down hierarchy (Graeber \& Wengrow, 2018).

Hunting and gathering societies have been of key interest in anthropology since early onwards. It is important to note that not all of them are organized in an egalitarian way, and some of them show a high degree of inequality. Moreover, Woodburn (1982) notes that the equality is asserted. He distinguishes the hunting and gathering societies according to the timeline of return systems into immediate-return and delayed-return-systems. The first category is assigned to societies like Mbuti Pygmies of Zaire, the Kung Bushmen of Botswana and Namibia, the Pandaram and Paliyan of South India, the Batek Negritos of Malaysia and the Hadza of Tanzania. These societies share four characteristics of social organizing:

"(1) Social groupings are flexible and constantly changing in composition. (2) Individuals have a choice of whom they associate with in residence, in the food quest, in trade and exchange, in ritual contexts. (3) People are not dependent on specific other people for access to basic requirements. (4) Relationships between people, whether relationships of kinship or other relationships, stress sharing and mutuality, but do not involve long-term binding commitments and dependencies of the sort that are so familiar in delayed-return systems" (Woodburn, 1982: 434, emphasis in the original).

The focus is on the immediate-return-societies as they have an outstanding level of equality. There is a notable tendency to get rid of dissimilarities in regards to wealth, power and status. Nomadism is an essential factor. People live in small camp units, which are fluid. All men have access to weapons in four out of the above listed six societies. There is no aim at accumulating property. There are either no leaders or leaders who are well watched are not to use any authority nor to obtain material goods or fame. "Leaders should ideally be 'modest in demeanor, generous to fault, and egalitarian ... (Lee, 1979:350). "Leaders such as these pose no threat to egalitarian values and indeed could be said to display and reinforce egalitarianism" (Woodburn, 1982: 445). The so-called acephalous societies (stateless or leaderless) have two entities of government: the council of elders and the village assembly. In many of these societies, there is a clear separation between power and authority.

But, do egalitarian societies and organizations exist? According to Laloux, none of the organizations that he studied is non-hierarchical and there are differences in power. He concludes it's not the aim that everybody is equal (2015: 135). The question to ask is "How can everyone be powerful?" opposed to whether power is equally shared. This new paradigm could also be helpful for increasing gender equality. 
Owing to the structural changes, class ceilings might vanish and the gender pay gap could reduce due to the remuneration transparency and the peer-based processes. The German publications (e.g. Pircher, 2018) on this topic partly emphasize a male biased language. In others (e.g. Hauser, 2017), there is gender sensitivity in the general chapters but case studies mirror the current situation in organizations and hence talk about male managers and CEOs. Laloux applies a gender-sensitive language. Language as a powerful creator of realities could be used strategically in this paradigm shift to increase workplace diversity. "Changes in work organization may improve women's situation, produce negative discrimination in new forms or even produce new forms of negative discrimination" (Czarniawska ,2008: 116). Whether or not, this new paradigm continues the gender imbalance, improves the situation or creates new forms of negative discrimination could be studied in more detail in future.

\section{Community}

In 1955, G. A. Hillery collected 94 definitions of the term "community": "Beyond the concept that people are involved in community, there is no complete agreement as to the nature of community" (Hillery, 1955:119; Turner, 1969: 371). Buber (1961: 51; Turner, 1969: 371, emphasis in the original) "Community is the being no longer side by side (and, one might add, above and below) but with one another of a multitude of person. And this multitude, though it moves towards one goal, yet experiences everywhere a turning to, a dynamic facing of, the others, a flowing from I to Thou." Turner accented that communitas can only be understood in relationship to structure. The today's fascination of self-organized entities in organization with characteristics of a communitas might be rooted in the understanding that it eliminates "the norms that govern structured and institutionalized relationships and is accompanied by experience of unprecedented potency" (Turner, 1969: 372). The interrelatedness of human beings results from people attending completely in their wholeness. This corresponds to Laloux's description of wholeness as one of the key breakthroughs of the Teal-Organization.

\section{Authenticity \& Vulnerability}

The role of the CEOs changes significantly in an organization with the new paradigm. They have given up their traditional hierarchal power but at the same time they play a vital role, as they hold space for the self-organization to unfold. $\mathrm{S} / \mathrm{h}$ h is asked to be a good role model and in addition $\mathrm{s} / \mathrm{he}$ can choose roles just like anybody else in the organization. Moreover, the CEO often continues to be the public representative of the company for clients, suppliers, etc (Laloux, 2015: 240). Trusting instead of controlling is being described as the biggest challenge. Turner describes that a senior chief among the Ndembu in Africa represents the forefront of the society (in regard to the politico-legal hierarchy) and at the same time the unstructured total community. This paradox can be found in many African societies (Turner, 1969: 361). "Even when a man has become a chief, he must still be a member of the whole community of persons, and show this by 'laughing with them', respecting their rights, 'welcoming everyone', and sharing food with them" (Turner, 1969: 365). This comparison reveals that the new role of the CEO in the new paradigm of organizing is not a complete new social role at all.

Understanding how the concept of managers is constructed and sustained has been an anthropological focus (Ouroussoff, 1997; Ho, 2009; Jackall, 2010) before and that the moral positioning is highly influenced by the working environment. It has been studied how an atmosphere of fear and risk of losing one's job has turned into systems of "organized irresponsibility" (Jackall, 2010: 239). The new forms of organization, however, ask for authenticity. The work along tensions requires the willingness to be vulnerable. Vulnerability is seen as strength. The power of vulnerability has been profoundly researched by Brene Brown $(2010,2012)$ and she not only debunks the myth that vulnerability is a weakness but she also offers ways of how to rehumanize work by combating shame, removing blame, and participating in active feedback. 


\section{Personhood}

In the organizational concept of Laloux, the concept of personhood is extended to the company as he recommends $(2015: 283)$ that it might be beneficial to be silent and listen to what the organization reveals as its purpose. This corporate search for a soul is not new (Foster, 2017: 125) and it leads to the questions "which persons were to be identified with the corporation, Workers, Directors, or Shareholders?" These new forms of organization suggest that all can be identified as members of the corporation. In some cases (i.e. Premium Cola) this is extended to other stakeholders (clients and suppliers).

It might be worth further examining whether the application of the concept of personhood following Marilyn Strathern's research in Melanesia is of use to the new identities composed of several roles. She describes a concept of divisible, aggregated selves. "Personhood is transactional, created through relations of exchange" (Foster, 2017: 126). Shifting from job titles to roles, this multifaceted "dividuals", (a term that Strathern derived from McKim Marriott and used "to describe persons understood as nodes in a given matrix of relations. "(Foster, 2017: 127) could be a helpful frame to look into the newly formed relationships. Turning to the examples of foreign societies to provide solutions to current challenges of one's own society is a time-honored practice of anthropologists.

\section{Culture}

Organizational or corporate culture is a term that is widely used in business and management studies and literature. This term was influenced by anthropologists. However, there are two very distinct versions of this concept: 1 . An organization has culture - therefore it is the property of the management, and an independent controllable variable. It is produced by the leader and the culture results in harmony and consensus. 2. An organization is culture: culture is a social process and it includes everything that the organization possesses. It results from the negotiation of all members and culture produces conflict. It is useful because it helps to make sense of reality (Smircich, 1983).

Laloux (2015: 34) describes a strong shared organizational culture as the glue that keeps empowered organization together. In these new forms of organizations, culture "is both less necessary and more impactful (...). Less necessary because culture is not needed to overcome the troubles brought about by hierarchy. And more impactful, for the same reason - no energy is gobbled up fighting the structure, and all energy and attention brought to organizational culture can bear fruit. From a Teal perspective, organizational culture and organizational systems go hand in hand, and are facets of the same reality both are equally deserving of conscious attention." (Laloux, 2015: 229).

Corporate culture research has a long tradition in the field of anthropology (i.e. Arnsberg and Chapple, Gardner and Warner - all in the 1950s, Jordan, 2003: 11f) and the anthropological approaches have had sustainable impact on organization studies. There are tools and concepts to explore the organizational culture as well as the organizational systems and anthropologists have the ability to give them the needed open-minded, reflective attention.

\section{Reciprocity \& Trust}

Reciprocity has been a key theme in anthropology (Mauss, 1954; Sahlins, 1968). It has been shown that the rational choice theory cannot hold up against anonymous altruism and forms of gift-giving. Gifts bring along three types of responsibilities: giving, receiving and repaying. Companies following the new paradigm of organizing could be interesting sites for studying reciprocity. No matter which model is in use, the literature (Laloux, 2015; Hauser, 2017; Häusling, 2017; Pircher, 2018) and the people I spoke to all emphasize on the importance of trust as an essential attitude for the success of the new paradigm of organizing. It seems that in the beginning this will be affective trust based on goodwill, which later will be supplemented by cognitive trust based on proven competence, as the organizing principles evolve (Baba, 1999). Trust as a key to many societies and an interesting variable in any kind of exchange shifts from a nice to have asset to an absolute necessity. Trust is fostered when you give people space to get to 
know each other. The higher the level of trust, the lower the social distance; and usually we will find either generalized and/or balanced reciprocal relationships in these organizations (Krawinkler, 2013).

\section{Ambiguity \& Uncertainty}

The social processes in this new paradigm can be viewed as adventurous and risky. Risks can be distinguished between known and unknown risks. The first ones are the familiar ones, where the rational-choice approach is working. This section focuses on the unknown risks, how will an organization react if all the (e.g. remuneration) information is published transparently? Which turn is the company going to take if the CEO has no final veto in decisions? These are unknown risks. According to Boholm (2003), trusting the people in charge is one of the coping mechanisms. The others include avoiding the situation and/or taking precautions. This seconds that why trust is of such high importance in companies with a new alternative form of organization. There are a lot of situations that can be classified as risky and many of them cannot be dealt with in the traditional way. Trusting the process and the people replaces rational choices. Opening up processes also make the ambiguity visible. This challenges the positivist view of one true reality and opens the floor for the multiple realities that exist according to constructivists' view.

\section{Self-Organized}

Self-organization is the keyword in all these above described approaches. However, it is wrong to pretend that self-organization is something new. Already in the Hawthorne-Studies that shed light on the informal structure, it could be observed that workers collaborated and self-organized their work regarding output to not only meet company standards but also to secure a supporting and endurable work environment. Since then, it is common knowledge that all organizations have besides their formal organizational charts a second informal structure that is widely used in achieving companies' tasks and challenges ${ }^{12}$. So, in some successful cases, the new alternative forms of organization may be formalizing the informal structure - this would be an interesting field for further (business anthropological) research. Moreover, all societies in the world show some kind of self-organization. Self-organization, voluntary pooling, and reciprocal help - the basic elements of anarchism - have been known since human-kind existed. Whether or not new forms of organizing represent an application of anarchy to companies was another question posed. The study of anarchistic societies shows that they are not necessarily without hierarchy (e.g. the Tiv in Nigeria, whose households are hierarchically organized). Graeber (2012 [2005]) describes communities in the highlands of Madagaskar as self-organized, and local decisions were taken by consensus, the idea that adults could order other adults what to do was regarded as nonsense. Even though the society is not fully egalitarian, the accumulation of wealth and status is prevented by the belief that magic would fall a victim to magic. What we can learn from these societies is that keeping the scope of social differences narrow is a key to prevent turbulences and foster an egalitarian habitus. As we have seen before narrowing the range of remuneration and leveling the membership to a company (i.e. no more differentiation between white- and blue-colored members, no distinction between permanent staff and temporary staff) can be of high importance to the functioning of this new way of organizing.

\section{Useful Methods and Approaches}

The observation, analyses and theorizing of practices is a long-hold tradition in anthropology. Anthropologists are well equipped to help organizations enter this adventure of changing the paradigm. The widely cited anthropological culture approach for organization (an organization IS a culture) stating corporate cultures is a social process, which results from the negotiation of all members, produces conflicts, and helps to make sense of reality (Smircich, 1983), is the base to deal with the emerging complexity of realities in corporations. According to Barbara Czarniawska's performative definition of organizations (2008: 7-16), it is probably the time to study the process of organizing and not just organizations. Moreover, traditional anthropological training prepares being immersed in foreign cultures 
and societies, with little security in regards to knowledge of the rules, customs, cultural concepts, etc., that first need to be discovered and learned, while being able to step back to an analytical mode. In this process most of us have learned to view failures as means of information and honor them this way. Self-reflection is a steady part of our work and can be helpful in stirring self-reflection in others. Communication and acting as a translator and culture broker between different groups are other key assets. Ethnographic research involves regularly entering a field with an open-mind minimizing expectations (and being aware of those we carry) and hence open space for the unexpected but existing phenomena. Holding space to explore themes that are prone to being experienced as vulnerable is one more qualification in the various field researches. We are trained to deal with a high level of complexity and to look at topics holistically. Last but not least studying up ${ }^{13}$ has been a core method in anthropological research and this provides the ability to meet people at eye level.

\section{The New Paradigm of Management - A Global Approach?}

The methods applied in this new paradigm of organizing seem to be applicable across various cultures and organizations. Owen (2001) describes in detail that his method of open space has been influenced by his experiences as a photo journalist in West Africa, where he participated in the initiation ceremony of the boys. The smooth organization of this four days celebration raised his curiosity. Since then, he and others have used the open space technology in a number of different cultural settings in groups with a high level of diversity around the globe (Owen, 2001: 25) in groups from 5 to 1000 participants. Owen also explains that in his setting, he likes to use a talking stick for the closing circle. The talking stick tradition is a very old one that is documented as a communication practice of the Lakota people, and can be found in many other places as well. It allows that the person holding the stick (often a nicely decorated artifact) is entitled to speak and share whatever is important to her/him, and all the others listen. Then the stick is passed on to the next person and the circle stays together till everybody who wanted to share something has been heard. Storytelling as well as circles as a form of organization for communication and conflict settling is a common practice maybe as old as human communities, found in many of the indigenous cultures around the world.

Laloux's examples demonstrate that even companies with 40,000 employees in dozens of countries can be a so-called Teal organization.

This opens the field for further research on how the so-called new management paradigm that seems to origin from industrialized countries is applicable, received, and developed across the globe.

\section{CONCLUSION}

Already in 2008, Dirk Baecker, a German sociologist, who holds a chair in culture theory and management at the University of Witten, pointed out that we need new organizational theories for these new forms of organizations, in which the point of focus is the human being, which also include thoughts on the cultural forms of the society and the organization. This request has not yet been really answered. Books like the one from Laloux (2015) are a start but it should also be a request for business and organizational anthropologists, not least because we have the tools to study (corporate) cultures and practices. This new paradigm of organizing has to be lived to be explored, as its outcome cannot be controlled by individuals. Similarly, ethnography is an iterative process and therefore they might go well together.

Referring to the question Homo oeconomicus quo vadis? it might be helpful to summarize all these various concepts by a common term, sharing the main characteristics of the people involved in these new organizations ${ }^{14}$. An answer might be homo animus. Animus means "mind; intellect; soul; feelings; heart; spirit, courage, character, pride; air" (Whitaker, 1993-2007). This term seems appropriate for the purpose-driven, self-responsible and self-organized employees that act authentically, are interested in self-reflection and self-development, keen on collaboration and brave to show their vulnerability. 
Maybe in future, businesses are not being asked how much profit they made, how big their market share is, but if they have served their purpose. This proposal of the homo animus requires further research but seems to be valid after the intense studying of the case studies presented by Laloux (2015), Häusling (2017), Hauser (2017) and Pircher (2018).

This article aimed at providing a first discussion of the contemporary topic of so-called new alternative forms of organizations through the anthropological lens. It is important to note that the term is not clearly defined yet and even the approaches described in this paper are very heterogeneous and it might be necessary in future to refine the new paradigm of management. There are multiple questions arising from this mostly literature research and I look forward to the opportunity of doing some field research in this area. Ethnography including participant observations seems to be the primary choice: "It (...) is my belief that any group of persons - prisoners, primitives, pilots or patients - develop a life of their own that becomes meaningful, reasonable and normal once you get close to it, and that a good way to learn about any of these worlds is to submit oneself in the company of the members to the daily round of petty contingencies to which they are subject" (Goffman, 1968: 7).

We don't know yet how this new paradigm of management will be understood and put into practice internationally. But, even on a smaller scale, there are many areas of not-knowing and it would be vital to research them through interdisciplinary teams to provide an understanding and solutions to the contemporary challenges of organizing.

\section{ENDNOTES}

1. Stephanie A. Krawinkler, Dr., social and cultural anthropologist, author, and lecturer at the University of Applied Sciences BFI Vienna and at the University of Applied Sciences of WKW in Vienna, Austria. She has been conducting business anthropological research since 2006. Other fields of research include cross-cultural communication, methodology, trust, awareness, and South East Asia. s.krawinkler@gmail.com

2. Neuwaldegg is a consulting company that has been offering system theoretical support since many years. There is a strong link between the system theory and the way Holacracy views organizations. Hence, it is not very surprising that the former system theoretical consulting companies in Austria now all offer support for agile management, and Holacracy.

3. The new paradigm of management and the new paradigm of organization/organizing are terms that are used alternatively in this paper.

4. All of the 17 people were interested in non-documentative software development and included representatives from Extreme Programming, SCRUM, DSDM, Adaptive Software Development, Crystal, Feature-Driven Development, Pragmatic Programming, and other opened to this idea (Highsmith, 2001). SCRUM was developed by Ken Schwaber and Jeff Sutherland in the early 90s and is a "framework for developing complex products" (Sutherland \& Schwaber, 2017). Describing this and the other mentioned concepts is beyond the limits of this paper but further information can be found in the Scrum Guides, which are available in more than 35 languages. www.scrumguides.org

5. The Holacracy constitution can be found in eight languages at https://www.holacracy.org/constitution.

6. Ken Wilber formulated the integral theory in the 1970s, merging eastern religious traditions with western structural stage theory. His AQAL-Theory (All Quadrants All Levels) describes a holistic approach comprising "all quadrants (dimensions of reality: interior/exterior, individual/collective), all levels (of development), all lines (of development), all states (of consciousness, but also other states), all types (such as personality types, but also other types)." (The Ken Wilber Gratitude Fund, 2018).

7. Max Weber and Georg Simmel were formative for the social-scientific concept of VERSTEHEN.

8. Communitas is a term used by Turner (1969: 360) to differentiate "a certain modality of social relationship from an area of common living". They are characterized by a sense of egalitarism. Communitas is oriented in the present, whereas structure is linked to past and future. Even though Turner focused on preindustrial 
societies, he clearly states (1969: 370) that "communitas and structure are to be found at all stages and levels of culture and society."

9. This would be an interesting area to investigate further, studying how the different attitudes and levels of freedom and self-responsibility impact organizational cultures.

10. Describing these various methods is beyond the scope of this paper, but I sincerely invite the readers to investigate further themselves.

11. Premium wants to live and spread a fair, ecological and socially sustainable economic model in high quality.

12. At Wire Inc as in many other companies the after-work-pint meetings were an essential key for solving acute technical challenges quickly, that would have taken much longer in case of following strictly the formal hierarchy. (Krawinkler, 2012).

13. Studying up means studying the powerful as well as the powerless. (Nader, 1969)

14. Thanks to my colleague Ass. Prof. Dr. Lukas Zenk, who stirred that reflection.

\section{ACKNOWLEDGMENTS}

I thank my colleagues, Ass. Prof. Dr. Lukas Zenk (Danube University Krems) and Mag. Deniz Seebacher (University of Vienna, Dep. of Social and Cultural Anthropology) for their invaluable feedback and helpful discussions. Moreover, I thank all the people who shared their experiences working with new forms of organizing with me.

\section{REFERENCES}

Allen, David. 2001. Getting Things Done. New York: Penguin Books.

Baba, Marietta L. 1999. "Dangerous Liaisons: Trust, Distrust, and Information Technology in American Work Organizations." Human Organization. 58 (3): 331-346.

Bäcker, Dirk. 2008. Studien zur nächsten Gesellschaft. Orig.-Ausg., 2. [Dr.]. Frankfurt am Main: Suhrkamp (Suhrkamp Taschenbuch Wissenschaft, 1856).

Beck, Kent, et al. 2001. “Agile Manifesto.” Accessed March 27, 2018. http://agilemanifesto.org/

Bessen, Daniela. 2018. "BessenTalk: 015 - PREMIUMCOLA KOLLEKTIVISTEN ELENA UND MIGUEL ÜBER KONSENS-DEMOKRATIE.” Accessed April 16, 2018.

https://www.bessen-chain.de/podcast/015-premiumcola-kollektivisten-elena-und-miguel-ueber-k onsens-demokratie/.

Boholm, Asa. 2003. "The Cultural Nature of Risk: Can There be an Anthropology of Uncertainty?" Ethos, 68 (2): 159-178.

Brown, Brene. 2010. “TedXHouston: The Power of Vulnerability.” Accessed April 4, 2018

https://www.ted.com/talks/brene_brown_on_vulnerability.

Brown, Brene. 2012. Daring Greatly: How the Courage to Be Vulnerable Transforms the Way We Live, Love, Parent, and Lead. New York City, NY: Gotham.

Czarniawska, Barbara. 2008. "A Theory of Organizing.' Cheltenham/Northampton: Edward Elgar.

Dwarfsandgiants. 2018 "Dwarfs and Giants. Rewriting the Future of Organization." Accessed on March 28, 2018. http://www.dwarfsandgiants.org/.

Dwarfsandgiants. 2018. “Glassfrog: Ansicht Organisation.” Accessed on March 28, 2018 https://de.glassfrog.com/organizations/1664.

Foster, Robert J. 2017. "The Corporation in Anthropology." In The Corporation. A Critical, Multi-Disciplinary Handbook, edited by Baars, Grietje \& Spicer, André, 111 - 133. Cambridge University Press.

Gebauer, Jana. 2016. "Diese Cola Will ich nicht. OXI Wirtschaft Anders Denken.” Accessed on_April 16, 2018. https://oxiblog.de/diese-cola-will-ich-nicht/. 
Goffman, Ervin. 1968. Asylums. Harmondsworth: Penguin.

Graeber, David. 2012[2005]. 'Frei von Herrschaft.'Fragmente einer anarchistischen Anthropologie. Wuppertal: Peter Hammer Verlag.

Graeber, David \& Wengrow, David. 2018. "How to Change the Course of Human History." Eurozine. 2. March 2018. Accessed April 16, 2018. https://www.eurozine.com/change-course-human-history/.

Hall, Edward T. 1976. Beyond Culture. Garden City, N.Y. : Anchor Press.

Hauser, Christian. 2017. Neue Organisationsformen von Arbeit mit Fokus auf hierarchiefreie und hierarchiereduzierte Unternehmen in Österreich. Masterarbeit. Sigmund Freud Privatuniversität.

Häusling, André, ed. 2018. Agile Organisationen. Transformationen erfolgreich gestalten - Beispiele agiler Pioniere. Freiburg: Haufe.

Ho, Karen. 2009. Liquidated: An Ethnography of Wall Street. Durham, NC: Duke University Press.

HolacracyOne. 2018. "Holacracy." Accessed March 28, 2018. https://www.holacracy.org.

HolacracyOne. 2018. "Organization.” Accessed March 28, 2018. https://app.glassfrog.com/organizations/5.

Highsmith, Jim. 2001. "History: The Agile Manifesto.” Accessed March 28, 2018. http://agilemanifesto.org /history.html.

Jackall, Robert. 2010. Moral Mazes: The World of Corporate Managers. Oxford: Oxford University Press.

Krawinkler Stephanie A. 2013. Trust is a choice. A Prolegomena of Anthropology of Trust(s). Heidelberg: Carl-Auer-Verlag.

Laloux, Frederic. 2015. Reinventing Organizations. A Guide to Creating Organizations inspired by the Next Stage of Human Consciousness. Brussels: Nelson Parker.

Malinowski, Bronislaw. 1961[1922]. Argonauts of the Western Pacific. New York: E. P. Dutton.

Mauss, Marcel. 1954. The Gift: Forms and Functions of Exchange in Archaic Society. London: Cohen \& West Ltd.

McGregor, Douglas. 1960. The human Side of Enterprise. New York, NY: McGraw-Hill.

Nader, Laura. 1969. "Up the Anthropologist: Perspectives Gained From Studying up." In Reinventing Anthropology, edited by Dell Hymes, 284-311. New York: Pantheon Books.

Owen, Harrison. 2001. Open Space Technology - Ein Leitfaden für die Praxis [1997: Open Space Technology. A User's Guide]. Stuttgart: Klett-Cotta.

Ouroussoff, Alexandra. 2010. Wall Street at War: The Secret Struggle for the Global Economy. Cambridge: Polity.

Pircher, Richard. 2018. Agilstabile Organisationen Der Weg zum dynamischen Unternehmen und verteilten Leadership. Vienna: Verlag Franz Vahlen (in print).

Premium. Accessed April 16, 2018. http://www.premium-cola.de/.

Robertson, Brian. 2017. "The Humanity of Holacracy.” Blog 6, March 2017. Accessed March 28, 2018.

https://blog.holacracy.org/holacracys-human-side-36d601882d21.

Rogall, Holger \& Gapp, Katharina. 2015. "Homo Heterogeneous - das neue Menschenbild der Ökonomie.” In Wirtschaftsanthropologie, edited by Claus Dierksmeier, 99-115. Baden-Baden: Nomos-Verlag.

Rössner, Michael \& Uhl, Heidemarie, ed. Renaissance der Authentizität? Über die neue Sehnsucht nach dem Ursprünglichen. Bielefeld: Transcript.

Sahlins, Marshall. 1968. Tribesmen. Englewood Cliffs N.J.: Prentice-Hall.

Sahlins, Marshall. 1972. Stone Age Economics. New York: Aldine.

Seiser, Getraud. 2017. "Eine Knappe Theoriegeschichte der Ökonomischen Anthropologie." In Ökonomische Anthropologie. Einführung und Fallbeispiele, edited by Gertraud Seiser, 23-53. Vienna: Facultas.

Schreyögg, Georg. 2016. Grundlagen der Organisation. Basiswissen für Studium und Praxis. Wiesbaden: Springer-Verlag. 
Smircich, Linda. 1983. "Concepts of Culture and Organizational Analysis." Administrative Science Quarterly, 28: 339-59.

Sociocracy. "Sociocracy. A Deeper Democracy." Accessed March 27, 2018. http://www.sociocracy.info.

Sutherland, Jeff \& Schwaber, Ken. 2017. "Scrum Guides.” Accessed March 27, 2018. http://www.scrumguides.org.

The Ken Wilber Gratitude Fund. 2018. "Integral Theory.” Accessed March 6, 2018. https://www.kenwilberfund.org/integral-theory/.

The Sociocracy Group. "Sociocracy.” Accessed March 27, 2018. http://thesociocracygroup.com/.

Turner, Victor. 1969. The Ritual Process: Structure and Anti-Structure. Chicago: Aldine Publishing.

Wiki. "A wiki to Inspire Next Generation Organization.” Accessed April 2, 2018. http://reinventingorganizationswiki.com/Main_Page.

Whitaker, William. 1993-2007. "William Whitaker's Words. University of Notre Dame." Accessed April 2, 2018. http://www.archives.nd.edu/cgi-bin/wordz.pl?keyword=animus.

Woodburn, James. 1982. "Egalitarian Societies.” Man. New Series. 17(3): 431-451. 